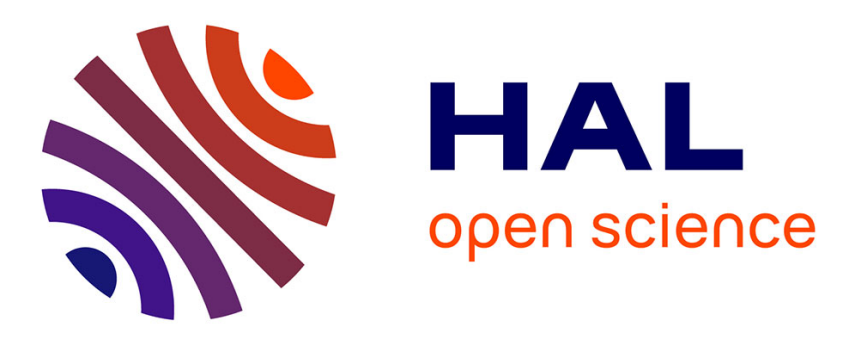

\title{
2q31.1 microdeletion syndrome- redefining the associated clinical phenotype
}

Boyan I Dimitrov, Irina Balikova, Thomy de Ravel, Hilde van Esch, Maryse de Smedt, Emiel Baten, Joris R Vermeesch, Irena Bradinova, Emil Simeonov, Koen Devriendt, et al.

\section{To cite this version:}

Boyan I Dimitrov, Irina Balikova, Thomy de Ravel, Hilde van Esch, Maryse de Smedt, et al.. 2q31.1 microdeletion syndrome- redefining the associated clinical phenotype. Journal of Medical Genetics, 2010, 48 (2), pp.98. 10.1136/jmg.2010.079491 . hal-00584725

\section{HAL Id: hal-00584725 \\ https://hal.science/hal-00584725}

Submitted on 10 Apr 2011

HAL is a multi-disciplinary open access archive for the deposit and dissemination of scientific research documents, whether they are published or not. The documents may come from teaching and research institutions in France or abroad, or from public or private research centers.
L'archive ouverte pluridisciplinaire HAL, est destinée au dépôt et à la diffusion de documents scientifiques de niveau recherche, publiés ou non, émanant des établissements d'enseignement et de recherche français ou étrangers, des laboratoires publics ou privés. 


\section{2q31.1 microdeletion syndrome- redefining the associated clinical phenotype}

Boyan Dimitrov ${ }^{1}$, Irina Balikova ${ }^{1}$, Thomy de Ravel $^{1}$, Hilde Van Esch ${ }^{1}$, Maryse De Smedt $^{1,2}$, Emiel Baten ${ }^{3}$, Joris Robert Vermeesch ${ }^{1}$, Irena Bradinova ${ }^{4}$, Emil Simeonov $^{4}$, Koen Devriendt ${ }^{1}$, Jean-Pierre Fryns ${ }^{1}$ and Philippe Debeer ${ }^{1,5}$

${ }^{1}$ Centre for Human Genetics, University Hospitals, K.U. Leuven, 3000 Leuven, Belgium

${ }^{2}$ AZ Sint-Augustinus, 2610 Wilrijk, Belgium

${ }^{3}$ Sint Lucas Hospital, 8310 Bruges, Belgium

${ }^{4}$ University Hospital Aleksandrovska, Department of Paediatrics, Medical University Sofia, 1431 Sofia, Bulgaria

${ }^{5}$ Department of Musculoskeletal Science, Division of Orthopedics, University Hospitals, K.U. Leuven, 3212 Pellenberg, Belgium

Corresponding author: Prof. Dr. Philippe Debeer, Centre for Human Genetics, University Hospitals Leuven, Herestraat 49, 3000 Leuven, Belgium e-mail: Philippe.Debeer@uzleuven.be

Key words: $H O X D 13$, synpolydactyly, limb defects, 2q31.1 deletion syndrome Running title: 2q31.1 microdeletion syndrome

Word count: 3423 


\begin{abstract}
Introduction: The clinical phenotype of the chromosome 2 q31 deletion syndrome consists of limb anomalies ranging from monodactylous ectrodactyly, brachydactyly and syndactyly to camptodactyly. Additional internal organ anomalies, e.g. heart defects, ocular anomalies may be present. Hemizygosity for HOXD13 and EVX2 genes was thought to cause the observed skeletal defects. Recently, based on the phenotype of patients with overlapping 2q31 interstitial deletions, a new SHFM5 locus was proposed- proximal to the HOXD cluster, between EVX2 and marker D2S294. DLX1 and DLX2 haploinsufficiency was suggested as the most plausible explanation for the observed SHFM-like limb anomalies in these cases.
\end{abstract}

Methods and Results: Five unique, interstitial 2q31 deletion patients were selected to further characterize the $2 \mathrm{q} 31$ region and to establish a genotype/phenotype correlation map. The size of the deletions was delineated with a chromosome 2 specific tiling path BAC array. The clinical and molecular data for this group of patients were compared to others in the literature. A common locus for the observed skeletal anomalies, including the $H O X D$ genes and surrounding regulatory sequences, was delineated. These results correlate with recently published studies in animal models. In addition, a critical region for the facial gestalt of the $2 \mathrm{q} 31.1$ microdeletion syndrome was delineated.

Conclusions: Our results reinforce the hypothesis that the variable skeletal phenotype in $2 \mathrm{q} 31$ deletion patients is a result of hemizygosity for the HOXD genes and that the 2q31.1 microdeletion syndrome is a well defined and clinically recognizable phenotype. 


\section{INTRODUCTION}

Several patients with chromosome 2q31 interstitial deletions have been described. The clinical phenotype was first further delineated by Boles et al. [1] and consists of developmental delay, facial dysmorphism, a variety of limb defects and other internal organ anomalies affecting the brain, eyes, heart, and the uro-genital system $[1,2]$. Remarkably, the spectrum of upper/ lower limb abnormalities can range from (1) ectrodactyly/ monodactyly, through (2) syndactyly and (3) brachydactyly to (4) isolated camptodactyly or (5) clinodactyly. The HOXD cluster was initially accepted as a major candidate responsible for the observed abnormal limb morphogenesis [1, 3]. Genes important for the mental, cranio-facial and heart development were thought to be located more proximally on chromosome 2 q24 [2].

Recently, based on the phenotype of patients with overlapping interstitial deletions of the 2q31 region, a new locus responsible for split foot-hand malformation (SHFM) was proposed-SHFM5. It was positioned proximally to the HOXD cluster between EVX2 and marker D2S294 thus including DLX1 and DLX2. The last two genes have been suggested as the most probable candidates causing the phenotype [4].

In an attempt to investigate further the phenotype/ genotype correlations at the $2 \mathrm{q} 31$ region and to refine the hypothetical SHFM5 locus, the $2 \mathrm{q} 31$ aberrations in five patients were compared with those of published $2 q 31$ deletions $[4,5,6,7,8,9,10,11$, $12,13,14,15,16]$. We were able to show that hemizygosity of only the HOXD genes and/ or HOXD regulatory sequences in vicinity $[17,18]$ is responsible for the observed limb defects in these individuals. Even more, for the first time we demonstrate that the $2 \mathrm{q} 31.1$ microdeletion is a clinically recognizable contiguous gene syndrome, consisting of two partially overlapping but distinct loci responsible for the specific facial gestalt and skeletal abnormalities.

\section{MATERIALS AND METHODS}

\section{Clinical reports}

All five patients have been examined by at least one of the authors and long term follow-up was available for all individuals.

\section{Patient 1}

This boy is the first child of healthy and young Caucasian parents. Birth weight was $3.500 \mathrm{~kg}$ (P25-P50) and the length $49 \mathrm{~cm}(\mathrm{P} 3-\mathrm{P} 10)$. At the age of 4 and $1 / 2$ years he had short stature $(<\mathrm{P} 3)$ and moderate to severe mental retardation, no speech, 
generalised muscular hypotonia, head circumference between P3-P10, thin, sparse hair, a prominent forehead, ptosis, down-slanting palpebral fissures, a bulbous nasal tip, cleft soft palate, open mouth with downturned corners, everted and thick lower lip, low-set ears with large lobes, short neck with low-set hair line, camptodactyly, bilateral fifth finger clinodactyly, and bilateral syndactyly of toes II-V. In addition, a ventricular septal defect closed spontaneously (figure 1a-d).

MRI imaging revealed a complex brain anomaly with hydrocephaly, hypoplastic corpus callosum, small sella tursica with hypoplastic pituitary gland and an ectopic neurohypophysis (figure 1e).

$\mathrm{X}$-rays of hands and feet showed delayed bone age, relatively elongated proximal and hypoplastic middle phalanges particularly of the second and fifth fingers, irregular ossification of tarsal bones, wide metatarsals with irregular metaphyses and epiphyses, widening of the first toe rays with very short first proximal phalanges, and absent middle phalanges of toes II-V (figure 1f,g).

High resolution karyotyping revealed a de novo interstitial deletion $2 \mathrm{q} 24.3 \mathrm{q} 31$.

\section{Patient 2}

The proposita is the second child of healthy parents. After a difficult pregnancy complicated with bleeding in the $12^{\text {th }}$ week, she was born by Caesarean section at the $36^{\text {th }}$ week of gestation because of transverse position of the foetus. There were signs of prematurity. Her birth weight was $1.900 \mathrm{~kg}$ (P3-P10), length $41 \mathrm{~cm}(<\mathrm{P} 3)$ and head circumference $29 \mathrm{~cm}(<\mathrm{P} 3)$. Due to adaptation problems she was admitted to the neonatal intensive care unit for a short period. The mother had one previous miscarriage and a normal older daughter from another relation. Patient 2 was referred to the Genetic Clinic because of developmental delay, microcephaly $(<\mathrm{P} 3)$ and facial dysmorphism characterised by a narrow forehead with a prominent metopic suture resulting in a trigonocephalic shape of the head, downslanting palpebral fissures, hypotelorism, shallow orbits with protruding eyes, ptosis, asymmetric pupils ( $\mathrm{R}>\mathrm{L})$, bulbous nasal tip with a small pit, protruding ears with simple pinnae, a thin upper lip, downturned corners of the mouth and mild micrognathia (figure 1h,i). The left foot had complete cutaneous syndactyly II-V. On the right foot there was only soft tissue-syndactyly of the second and third toes. Both halluces looked larger and were separated by a wide gap from the second digit ("sandal gap" sign) (figure $1 \mathrm{j}, \mathrm{k}$ ). In addition, there were also two flat pre-sacral haemangiomata, dimples on both elbows, and a ventriculo-septal heart defect that closed spontaneously. At two years of age her 
height was below the third percentile $(<\mathrm{P} 3)$ and she had thin hair. There was marked microcephaly $(<\mathrm{P} 3)$ and developmental delay with a developmental age of seven months. A conventional G-banded karyotype was normal.

Babygram and X-rays of lower limbs showed short second and fifth middle phalanges of the hands, wide first toe rays, short and broad first metatarsals, short, bullet-like middle phalanx of the first toes and absent ossification centres of II-V digits of the feet (figure 11). Brain imaging revealed abnormal cortical gyration and periventricular cyst lesions affecting the thalami (figure $1 \mathrm{~m}$ ).

\section{Patient 3}

The third patient is the second child of healthy and young Caucasian parents. She was born at 37 gestation weeks with a birth weight of $3.000 \mathrm{~kg}$ (P50), length of $49 \mathrm{~cm}(\mathrm{P} 25-$ P50) and head circumference of $34 \mathrm{~cm}$ (P25-P50). Due to severe neonatal hypotonia, feeding problems and an increased risk for Sudden Infant Death Syndrome she was on monitoring until the age of four months. Over the years she developed a progressive thoraco-lumbar scoliosis with short stature, persistent hypotonia, hyperlaxity and tapering fingers. At 131/2 years clinical re-evaluation revealed a standing height at the

$3^{\text {rd }}$ centile, truncal hypotonia, a prominent thoracic kyphoscoliosis, and elongated asymmetric face with long nose, high nasal bridge, full lower lip and retrognathia (figure $1 \mathrm{n})$. There was developmental delay and microcephaly $(<\mathrm{P} 3)$. The hands had tapering fingers, mild syndactyly of digits III-IV and smooth palmar creases (figure 10). Short fifth metatarsals, increased distance between the first and second toes with medial deviation of the halluces and flat foot arches were present bilaterally (figure 1p). In addition she suffered from urinary infections and a urinary reflux was detected. A G-banded karyotype was normal and FMR-1 gene mutations were excluded.

\section{Patient 4}

Patient 4 is the eldest daughter of two children of non-consanguineous parents. Her brother is healthy. She has moderate intellectual disability with slow developmental milestones and is always good-humoured and continually active. She is unable to concentrate and therefore attends special education.

At 6 years of age her height was $106.5 \mathrm{~cm}$ (P3), weight $17 \mathrm{~kg}$ and head circumference $48 \mathrm{~cm}(<\mathrm{P} 3)$. She is thus microcephalic and displays downslanting palpebral fissures, epicanthus inversus, a fine nose bridge and a pointed chin (figure 1q,r). Her teeth are tightly packed. She has clinodactyly of the fifth fingers and foetal finger pads. 
No chromosomal abnormalities were detected by conventional karyotyping.

\section{Patient 5}

This girl is the second child of healthy, non-related parents. She was born at term with normal physical parameters after an uncomplicated pregnancy. At the age of 6 months, she was admitted to the hospital because of febrile seizures and anti-epileptic therapy was initiated. Clinical examination at the age of 9 months revealed developmental delay with pronounced hypotonia. She had a narrow thorax, a narrow forehead with a prominent metopic suture, a short nose with thin nares, depressed and wide nasal bridge, a long and smooth philtrum, blepharophimosis, epicanthic folds, nystagmus, strabismus, Duane anomaly, simple ears with uplifted ear lobules, a high arched palate, a small tent-shaped mouth, micrognathia, and relatively small hands and feet (figure 1s,t). Both the head circumference and length were at the $25^{\text {th }}$ centile (P25). High resolution karyotyping did not reveal any abnormalities.

\section{DNA extraction}

Blood DNA was extracted according to standard protocols.

\section{Array CGH analysis}

Genomic screening for $\mathrm{CNVs}$ was performed using a homemade $1 \mathrm{Mb}$ array $\mathrm{CGH}$ platform. Fine mapping of the breakpoints was done by chromosome 2 specific tiling path BAC array. All hybridizations and analyses were done as previously described [19]. The aberrations discussed below are given as the maximum size defined as by the first flanking non-deleted BAC clones on the tiling path array CGH platform (a normal $\log 2$ ratio).

\section{FISH analysis}

Confirmation of the $1 \mathrm{Mb}$ array CGH results was done by FISH analysis. BACs were labelled with Spectrum Orange ${ }^{\mathrm{TM}}$ - dUTP (red signal) or Spectrum Green ${ }^{\mathrm{TM}}$ - dUTP (green signal) and hybridized on metaphase chromosomal spreads as described [20].

\section{RESULTS}

High resolution standard karyotyping revealed a 2q31 chromosomal aberration in Patient 1 . Subsequently, a $1 \mathrm{Mb}$ array CGH analysis confirmed this and excluded the presence of other submicroscopic copy number variations that would contribute in 
addition to the phenotype of this individual. The $2 \mathrm{q} 31$ microdeletions of Patients 2-5 were detected by routine $1 \mathrm{Mb}$ array $\mathrm{CGH}$ screening. In all five individuals, the detected chromosomal abnormalities were de novo.

Chromosome 2 tiling path array $\mathrm{CGH}$ analysis was carried out to define the correct size of the deleted segments. The results were consistent with those of the $1 \mathrm{Mb}$ array CGH screening. All analyzed individuals had different sized 2q31 aberrations. No common breakpoints were observed and no common genomic mechanism can be proposed for the occurrence of these deletions (figure 2a) [21].

An 11.36Mb interstitial deletion flanked by BACs RP11-656M07 and RP11-600I19 was detected in Patient 1. This aberration removes 134 genes including $D L X 1, D L X 2$ and the entire $H O X D$ cluster on chromosome $2 \mathrm{q} 31.1$ and extends from band $2 \mathrm{q} 31.1$ to band 2q31.3 (figure 2a).

Patient 2 carried the largest deletion which removes $16.9 \mathrm{Mb}$ on chromosome $2 \mathrm{q} 31.1$ q32.1 from BACRP11-703L16 to BAC RP1189E07, thus encompassing 140 genes. The $H O X D$ and $D L X$ were present in a hemizygous state (figure 2a).

Patient 3 had a complex karyotype. A $2.74 \mathrm{Mb}$ deletion on chromosome $2 \mathrm{q} 31.1 \mathrm{q} 31.2$ (between BACs RP11-118L08 and RP11-592D06) was found. The detected aberration starts $59 \mathrm{~Kb}$ proximal to the EVX2 gene and extends to the TNN gene (figure 2a). There was an additional deletion of chromosome 16p13.11 with a minimum size of $1.9 \mathrm{Mb}$ (between BACs RP11-489O1 and RP11-288I13) and maximum size of 7Mb (between BACs RP11-174B4 and RP11-489A11). This aberration is identical to the recently described microdeletions in this locus which are a predisposition factor for developmental disabilities [22]. The reciprocal duplications are likely benign polymorphisms. No consistent limb abnormalities were found in individuals carrying either 16p13.11 deletions or duplications [22]. FISH analysis with BAC RP11-49401 (chromosome 16p13.11) and BAC RP11-157E8 (chromosome 2q31.1) labelled with Spectrum Orange ${ }^{\mathrm{TM}}$-dUTP was used to confirm the $1 \mathrm{Mb}$ array $\mathrm{CGH}$ results (data not shown).

In Patients 4 and 5, a 6.32Mb deletion on chromosome 2q24.3q31.1 (between BACs RP11-760C21 and RP11-1E20) and a 4.12Mb deletion on chromosome 2q31.1 (between BACs RP11-121K19 and RP11-388J7) were found, respectively. In both patients the detected aberration removed $D L X 1$ and $D L X 2$ genes but the HOXD cluster remained intact (figure $2 \mathrm{a}$ ). 
In two out of five patients in this study (Patients 1 and 2) there were mild limb defects associated with a deletion encompassing the HOXD, DLX1 and DLX2 genes. Thus the detected aberrations remove the entire SHFM5 locus proposed by Goodman et al. [4]. In one additional case with mild abnormalities of hands and feet (Patient 3 ) there was a 2q31.1 deletion affecting only the $H O X D$ cluster, but not $D L X 1$ and $D L X 2$. No limb defects were present in the remaining two individuals (Patients 4 and 5), who were carriers of a more proximal 2q31.1 deletion including $D L X 1$ and $D L X 2$ genes, but not the HOXD locus. In addition, we reviewed other published chromosome 2q31 deletion cases for who any molecular data for the size of the detected $2 \mathrm{q} 31.1$ aberration were available $[4,5,6,7,8,9,10,11,12,13,14,15,16]$. Alignment of the detected $2 \mathrm{q} 31$ deletions in our patients with those from the literature $[4,5,6,7,8,9$, $10,11,12,13,14,15,16]$ suggests that only the HOXD cluster and surrounding up-/ down-stream sequences are responsible for the observed Limb Anomalies (LA) in individuals with 2q31.1 microdeletions (figure 2a). The spectrum of upper limb defects includes clenched hands, shortening of middle phalanges leading often to clinodactyly of the fifth finger, brachy-metacarpy and partial cutaneous syndactyly. Absent middle and terminal phalanges, sometimes associated with nail hypoplasia, partial to complete cutaneous syndactyly II-IV, short metatarsals and wide first ray tubular bones are typical for the feet. Due to a digit hypoplasia and syndactyly, there could be a wide distance between the hallux and the remaining toes. This has been occasionally described as ectrodactyly [1,2]. Some affected individuals have fusions of phalanges, metatarsals and metacarpals. There is tendency for the lower limbs to be more often and more severely affected than the upper limbs (Supplemental table1). This critical LA locus starts $1.5 \mathrm{Mb}$ centromeric and $1 \mathrm{Mb}$ telomeric from the HOXD genes. Its maximum size extends from BAC RP11-388J7 (the first telomeric array $\mathrm{CGH}$ clone which is not deleted in Patient 4) to the breakpoint of patient 2 of Dlugaszewska et al. (2006) on chromosome 2q31 [23]. It includes all well defined HOXD regulatory elements such as the Global Control Region (GCR) and Proxy (Pr) with the Control sequences A (CsA), B (CsB), and C (CsC), as well as the hypothetical Earlier Limb Control Region (ELCR) (figure 2c) [17, 18, 24, 25]. Of interest, in four published patients with $2 \mathrm{q} 31.1$ microdeletions and limb defects [12, $13,14,15]$, the detected chromosomal aberration did not remove any of these currently known limb specific HOXD enhancers/ suppressors. Based on these findings 
and some preliminary data from animal models (Spitz- personal communications and references $[17,18,24])$, the presence of more regulatory elements involved in the limb development between the GCR and ATP5G3 gene, and downstream to the HOXD cluster is hypothesized (figure 2c). Indeed, there are several highly conserved sequences in tetrapods within this region and further research should unravel their importance for autopod development (not shown). In addition to the HOXD group, this specific LA locus harbours ten other genes. Two of them are associated with OMIM diseases (CHRNAI and CHN1). However, patients with 2q31 microdeletions do not share common features with any of these OMIM phenotypes.

Three individuals in this study had similar facial features (figure 1a,b,h,i,q,r - Patients 1, 2 and 4) including a narrow forehead, prominent metopic suture (variable), a small nose with bulbous tip, long and smooth philtrum, downslanting palpebral fissures, thin upper lip, thick and everted lower lip, low set and dysplastic ears, and micrognathia. A genotype/phenotype correlation, based on their phenotypes and patients in the literature $[4,5,6,7,8,9,10,11,12,13,14,15,16]$, reveals a common $2.4 \mathrm{Mb}$ locus for the observed common Facial Gestalt (FG) on chromosome 2q31.1 (Supplemental table1, figure 2a,b). Its maximum size extends from BAC RP11-1E20 (the first telomeric array CGH clone which is not deleted in Patient 5) to BAC RP11$388 \mathrm{~J} 7$ (the first telomeric array CGH clone which is not deleted in Patient 4).This critical FG region covers at least 15 known genes. Mutations in three of them are implicated in known OMIM disorders. Some of these "candidates" are transcription factors or are involved in the cell division cycle. Hence, they might be functionally important for the cranio-facial development. Of course, a positional effect of the detected 2q31 aberrations upon the function of genes in vicinity like $D L X 1$ and $D L X 2$ cannot be excluded since a partial facial phenotype could be observed in patients with $2 \mathrm{q} 31$ deletions ending in a close proximity to the defined critical FG locus in this study.

\section{DISCUSSION}

\section{Limb development and limb defects}

The $2.5 \mathrm{Mb}$ critical LA locus in patients with $2 \mathrm{q} 31.1$ deletions includes the HOXD genes and its regulatory sequences (figure 2c). A pure HOXD haploinsufficiency, due to hemizygosity for the HOXD cluster or its regulatory sequences, is the only 
plausible explanation for the disturbed limb development in these individuals. The patient's hand and foot defects are comparable with those of $H O X D$ haploinsufficient mutant mouse models [24, 26, 27]. This also explains their different and "less severe" limb anomalies in comparison with those in patients with HOXD13 mutations (polyalanine tract extension and point mutations) or small HOXD9-13 deletions [4, 28, 29, 30, 31, 32, 33]. These clinical observations correlate well with available animal models, functional studies and the principle for $H O X D$ functional colinearity $[29,30,32,33,34,35]$.

There were also a few published "atypical" cases that had more severe limb reduction anomalies described as a form of SHFM- monodactylous ectrodactyly [4, 7, 9]. They all carried larger 2q31deletions encompassing the HOXD cluster and extending in both centromeric and telomeric directions (Supplemental table 1, figure 2a). It was proposed that their limb defects were caused by gene at a new SHFM5 locus and $D L X 1$, and $D L X 2$ were suggested as the best candidates [4]. However our data do not confirm this possibility, since hemizygosity of the transcripts surrounding the HOXD genes at chromosome $2 \mathrm{q} 31.1$, but not including the HOXD cluster and its regulatory sequences, is not sufficient to produce any abnormal limb development (Patients 4 and 5). In addition, individuals with homozygous HOXD13 polyalanine tract expansions or patients with heterozygous mutations in both HOXD13 and HOXA13 present with hand and foot anomalies which partially overlap the severe limb defects in some patients with $2 q 31.1$ deletions $[36,37,38,39]$. Hence, mainly the HOXD haploinsufficiency should explain the more severe skeletal phenotype of these unusual cases.

Interestingly, there also are four published patients where different, apparently balanced de novo chromosomal rearrangements affecting the $2 \mathrm{q} 31.1$ locus were associated with skeletal defects [23, 40, 41]. Each of these individuals had a unique phenotype ranging from (1) mesomelic dysplasia [40, 41]; through (2) hand brachy/synpoly-dactyly (patient 1 of Dlugaszewska et al. [23]); to (3) severe terminal limb truncations similar to those described as SHFM- monodactylous ectrodactyly (patient 2 and patient 3 of Dlugaszewska et al. [23]). All chromosome 2q31.1 breakpoints were in close proximity to the HOXD cluster and none of the aberrations directly disrupted a known gene (figure 2a). The authors proposed that an abrogated function of centromeric or telomeric HOXD regulatory sequences would explain the corresponding preferential anomalies of hands/ feet or forearms/ lower legs [23]. Our 
results did not confirm this hypothesis since no segregation of observed limb defects was detected in patients with different chromosome 2q31.1 deletions (figure 2a and references $[12,13,14,15])$. We suppose that not just simply removing HOXD cluster regulatory sequences $[17,18,24,25]$, but more complex mechanisms (probably more than one) are responsible for this phenotypic variability in these affected individuals $[23,40,41]$. One possibility is a different genetic background such as cis- or transacting HOXD modifiers as mutations/ polymorphisms/ CNVs of other genes involved in the skeletal/ limb development [37, 42, 43]. Another option is a loss of limb specific regulatory sequences and adopting of new enhancers/ suppressors within the new genomic environment, thus leading to an aberrant/ neomorphic effect upon the HOXD function [44, 45, 46]. Last but not least, there could be a creation of chimera transcripts $[23,45,46]$ and/ or epigenetic modifications of the chromatin structure which was demonstrated to be important for the appropriate spatio-temporal and/ or colinear HOXD expression [47, 48, 49, 50]. The effect of one of these factors or the stochastic combination of more than a single event can trigger the observed discrepancy in the abnormal limb morphogenesis.

\section{Facial dysmorphism}

The facial gestalt in the 2q31 microdeletion syndrome is well-defined and clinically identifiable. Individuals that are hemizygous for the $2 q 31.1$ locus involved in the cranio-facial development (FG) share common features as described above (Supplemental table 1, figure2b). Despite this distinctive clinical pattern, it is difficult to assign a single gene within the defined critical FG region to the observed mental handicap and facial dysmorphism.

\section{Other abnormalities}

Congenital defects of the heart, brain and eyes, as well as clefts, scoliosis, an abnormal vertebral segmentation, craniosynostosis (very rare) and seizures are common but not specific. The presence and extent of these additional anomalies depends on the size and the direction of the detected 2q31 deletion (Supplemental table 1, figure 2a). Based on our data, we cannot link these clinical features to chromosome 2q31.1 region. Some of them, like seizures [8, 10] and heart defects [2], are often referred to up- and down-stream sequences outside the 2q31.1 microdeletion syndrome locus. Preliminary data suggest the presence of gene(s) located at chromosome 2q31.1 that may be involved in the brain and eye development (Delle Chiaie and Mortier- unpublished data). 
In conclusion, our results indicate that the detected common $2 \mathrm{q} 31.1$ microdeletion is a well-defined and clinically recognizable contiguous gene syndrome mapped to a specific genomic locus (figure $2 \mathrm{a}-\mathrm{c}$ ). The phenotype is characterized by moderate to severe developmental delay, microcephaly, short stature, hypotonia, specific facial gestalt and variable limb defects with distinct pattern (Supplemental table 1, figure 1a-m,q,r). This specific combination of clinical features is strongly suggestive for the correct diagnosis and appropriate genetic testing.

\section{Acknowledgements}

P.D., K.D. and H.V.E. are Clinical Investigators of the Fund for Scientific Research, Flanders, Belgium.

This work was supported by grant G019907N from the FWO-Vlaanderen to P.D. and in part by grants from the IWT (SBO-60848) and GOA/2006/12, and the SymBioSys Center of Excellence (Research Council, K.U.Leuven, EF/05/007) to J.R.V. and K.D. B.D. was partially supported by grant EO/06/32 of the K.U. Leuven, Belgium.

Competing Interest: none declared.

The Corresponding Author has the right to grant on behalf of all authors and does grant on behalf of all authors, an exclusive licence on a worldwide basis to the BMJ Publishing Group Ltd to permit this article (if accepted) to be published in JMG and any other BMJPGL products and sublicences such use and exploit all subsidiary rights, as set out in our licence (http://group.bmj.com/products/journals/instructionsfor-authors/licence-forms)." 


\section{Figure 1. Patients' phenotypes.}

A-G) Facial gestalt, complex CNS anomaly and limb defects of Patient 1 . There is hypoplasia of the second and fifth phalanges $(\mathrm{F})$, broad first toe ray, wide and short, bullet-like first proximal phalanges of both feet and absent middle toe phalanges II-V (G). H-K) Patient 2 at three months (H) and two years of age (I). She presents bilateral toe syndactyly II-IV $(\mathrm{J}, \mathrm{K})$, broad first metatarsals and first toe phalanges, wide and short (bullet-like) first proximal phalanges (L), absent ossification centres of middle phalanges II-V (L). Brain imaging shows cortical CNS abnormalities and bilateral periventricular cysts (M). N-P) Patient 3 has elongated and asymmetric face with long nose, and high nasal bridge (N). Mild syndactyly III-IV of hands (O) and bilateral hallux valgus, sandal gap, and short $5^{\text {th }}$ metatarsal are present $\left.(\mathrm{P}) . \mathrm{Q}-\mathrm{R}\right)$ Patient 4 at one year and four years, respectively (see the clinical report). S-T) Facies of patient 5 (see the text for more details).

\section{Figure 2. Chromosome 2q24.2-q32.3.}

A) Alignment (according Human Genome reference sequence from February 2009 GRCh37/hg19) of the $2 q$ deletions of patients $1-5$ and literature cases $[4,5,6,7,9,12$, 13, 14, 15, 16]. Black bars represent genes. Yellow lines mark patients without skeletal defects. Blue and green lines show patients with "typical" (ld- limb defects, pp- preaxial polidactyly), and severe limb defects (m/e- SHFM/ monodactylous ectrodactyly), respectively. The red line represents a patient with synpolydactyly (SPD) [4]. Red, green and orange ovals point to the $2 q 31$ breakpoints of patients carrying apparently balanced chromosomal translocations and an associated abnormal phenotype: mesomelic skeletal dysplasia (md) (orange) [40], SPD (red) [23], and SHFM/ monodactylous ectrodactyly (m/e) (green) [23], respectively. Transparent pink (facies) and yellow (limbs) vertical bars demarcate the FG and LA specific loci. Both regions with the candidate genes for cranio-facial and limb development are highlighted in sections (B) and (C) (according Human Genome build GRCh37/hg19). Genes associated with OMIM diseases are highlighted in red. In section (C) blue bars and red stars show the positions of HOXD regulatory sequences in mice as follow: GCR is for global control region, Pr for Prox, ELCR for early limb control region, and CsA, CsB and CsB for control sequence A, B, and C, respectively $[17,18,24]$. 


\section{REFERENCES}

1. Boles, R.G., Pober, B.R., Gibson, L.H., Willis, C.R., McGrath, J., Roberts, D,J,, Yang-Feng, T.L. Deletion of chromosome 2q24-q31 causes characteristic digital anomalies: case report and review. Am J Med Genet 1995;55:155-160.

2. Maas, S.M., Hoovers, J.M., van Seggelen, M.E., Menzel, D.M., Hennekam, R.C. Interstitial deletion of the long arm of chromosome 2: a clinically recognizable microdeletion syndrome? Clin Dysmorphol 2000;9:47-53.

3. Moller, M., García-Cruz, D., Rivera, H., Sánchez-Corona, J., Cantú JM. Pure monosomy and trisomy $2 \mathrm{q} 24.2-\mathrm{q} 31.5$ due to an inv/ins $(7 ; 2)(\mathrm{q} 21.2 ; \mathrm{q} 3105 \mathrm{q} 24.2)$ segregating in four generations. Hum Genet 1984;68:77-86.

4. Goodman, F.R., Majewski, F., Collins, A.L., Scambler, P.J. A 117-kb microdeletion removing HOXD9-HOXD13 and EVX2 causes synpolydactyly. Am J Hum Genet 2002;70:547-555.

5. Nixon, J., Oldridge, M., Wilkie, A.O., Smith, K. Interstitial deletion of $2 q$ associated with craniosynostosis, ocular coloboma, and limb abnormalities: cytogenetic and molecular investigation. Am J Med Genet 1997;70:324-327.

6. Slavotinek, A., Schwarz, C., Getty, J.F., Stecko, O., Goodman, F., Kingston H. Two cases with interstitial deletions of chromosome 2 and sex reversal in one. Am J Med Genet 1999;86:75-81.

7. Del Campo, M., Jones, M.C., Veraksa, A.N., Curry, C.J., Jones, K.L., Mascarello, J.T., Ali-Kahn-Catts, Z., Drumheller, T., McGinnis, W. Monodactylous limbs and abnormal genitalia are associated with hemizygosity for the human $2 \mathrm{q} 31$ region that includes the HOXD cluster. Am J Hum Genet 1999;65:104-110.

8. Pereira, S., Vieira, J.P., Barroca, F., Roll, P., Carvalhas, R., Cau, P., Sequeira, S., Genton, P., Szepetowski, P. Severe epilepsy, retardation, and dysmorphic features with a 2q deletion including SCN1A and SCN2A. Neurology 2004;63:191-192.

9. Bijlsma, E.K., Knegt, A.C., Bilardo, C.M., Goodman, F.R. Increased nuchal translucency and split-hand/foot malformation in a fetus with an interstitial deletion of chromosome $2 \mathrm{q}$ that removes the SHFM5 locus. Prenat Diagn 2005;25:39-44

10. Langer, S., Geigl, J.B., Wagenstaller, J., Lederer, G., Hempel, M., Daumer-Haas, C., Leifheit, H.J., Speicher, M.R. Delineation of a $2 q$ deletion in a girl with dysmorphic features and epilepsy. Am J Med Genet 2006;140:764-768. 
11. Mencarelli, M.A., Caselli, R., Pescucci, C., Hayek, G., Zappella, M., Renieri, A., Mari, F. Clinical and molecular characterization of a patient with a $2 \mathrm{q} 31.2-32.3$ deletion identified by array-CGH. Am J Med Genet 2007;143:858-865.

12. Svensson, A.M., Curry, C.J., South, S.T., Whitby, H., Maxwell, T.M., Aston, E., Fisher, J.,Carmack, C.E., Scheffer, A., Abu-Shamsieh, A., Brothman, A.R. Detection of a de novo interstitial $2 q$ microdeletion by CGH microarray analysis in a patient with limb malformations, microcephaly and mental retardation. Am J Med Genet 2007;143:1348-1353.

13. Pescucci, C., Caselli, R., Grosso, S., Mencarelli, M.A., Mari, F., Farnetani, M.A., Piccini, B., Artuso, R., Bruttini, M., Priolo, M., Zuffardi, O., Gimelli, S., Balestri, P., Renieri, A. 2q24-q31 deletion: report of a case and review of the literature. Eur J Med Genet 2007;50:21-32.

14. Monfort, S., Roselló, M., Orellana, C., Oltra, S., Blesa, D., Kok, K., Ferrer, I., Cigudosa, J.C., Martínez, F. Detection of known and novel genomic rearrangements by array based comparative genomic hybridisation: deletion of ZNF533 and duplication of CHARGE syndrome genes. $J$ Med Genet 2008;45:432-437.

15. Prontera, P., Bernardini, L., Stangoni, G., Capalbo, A., Rogaia, D., Ardisia, C., Novelli, A., Dallapiccola, B., Donti, E. 2q31.2q32.3 deletion syndrome: report of an adult patient. Am J Med Genet 2009;149:706-712.

16. Tsai, L.P., Liao, H.M., Chen, Y.J., Fang, J.S., Chen, C.H. A novel microdeletion at chromosome $2 \mathrm{q} 31.1-31.2$ in a three-generation family presenting duplication of great toes with clinodactyly. Clin Genet 2009;75:449-456.

17. Spitz, F., Gonzalez, F., Duboule, D. A global control region defines a chromosomal regulatory landscape containing the HoxD cluster. Cell 2003;113:405-417.

18. Gonzalez, F., Duboule, D., Spitz, F. Transgenic analysis of Hoxd gene regulation during digit development. Dev Biol 2007;306:847-859.

19. Van Buggenhout, G., Van Ravenswaaij-Arts, C., Maas, N.M.C., Thoelen, R., Vogels, A., Smeets, D., Salden, I., Matthijs, G., Fryns, J.P., Vermeesch, J.R. The $\operatorname{del}(2)(\mathrm{q} 32.2 \mathrm{q} 33)$ deletion syndrome defined by clinical and molecular characterization of four patients. Eur J Med Genet 2005;48:276-289.

20. Backx, L., Thoelen, R., Van Esch, H., Vermeesch, J.R. Direct fluorescent labelling of clones by DOP PCR. Mol Cytogenet 2008;1:3-6. 
21. Gu, W., Zhang, F., Lupski, J.R. Mechanisms for human genomic rearrangements. PathoGenetics 2008;1:4.

22. Hannes, F.D., Sharp, A.J., Mefford, H.C., de Ravel, T., Ruivenkamp, C.A., Breuning, M.H., Fryns, J.P., Devriendt, K., Van Buggenhout, G., Vogels, A., Stewart, H., Hennekam, R.C., Cooper, G.M., Regan, R., Knight, S.J., Eichler, E.E., Vermeesch, J.R. Recurrent reciprocal deletions and duplications of 16p13.11: the deletion is a risk factor for MR/MCA while theduplication may be a rare benign variant. J Med Genet 2009;46:223-232.

23. Dlugaszewska, B., Silahtaroglu, A., Menzel, C., Kubart, S., Cohen, M., Mundlos, S., Tumer, Z., Kjaer, K., Friedrich, U., Ropers, H.H., Tommerup, N., Neitzel, H., Kalscheuer, V.M. Breakpoints around the HOXD cluster result in various limb malformations. J Med Genet 2006;43:111-118.

24. Zákány, J., Kmita, M., Duboule, D. A dual role for Hox genes in limb anteriorposterior asymmetry. Science 2004;304:1669-1672.

25. Yamagishi, T., Ozawa, M., Ohtsuka, C., Ohyama-Goto, R., Kondo, T. Evx2Hoxd13 intergenic region restricts enhancer association to Hoxd13 promoter. PLoS One 2007;2:175.

26. Zákány, J., Duboule, D. Synpolydactyly in mice with a targeted deficiency in the HoxD complex. Nature 1996;384:69-71.

27. Kmita, M., Fraudeau, N., Hérault, Y., Duboule, D. Serial deletions and duplications suggest a mechanism for the collinearity of Hoxd genes in limbs. Nature 2002;420:145-150.

28. Goodman, F., Giovannucci-Uzielli, M.L., Hall, C., Reardon, W., Winter, R., Scambler, P. Deletions in HOXD13 segregate with an identical, novel foot malformation in two unrelated families. Am J Hum Genet 1998;63:992-1000.

29. Caronia, G., Goodman, F.R., McKeown, C.M., Scambler, P.J., Zappavigna, V. An I47L substitution in the HOXD13 homeodomain causes a novel human limb malformation by producing a selective loss of function. Development 2003;130:1701-1712.

30. Johnson, D., Kan, S.H., Oldridge, M., Trembath, R.C., Roche, P., Esnouf, R.M., Giele, H., Wilkie, A.O. Missense mutations in the homeodomain of HOXD13 are associated with brachydactyly types D and E. Am J Hum Genet 2003;72:984-997. 
31. Kan, S.H., Johnson, D., Giele, H., Wilkie, A.O. An acceptor splice site mutation in HOXD13 results in variable hand, but consistent foot malformations. Am J Med Genet 2003;121:69-74.

32. Zhao, X., Sun, M., Zhao, J., Leyva, J.A., Zhu, H., Yang, W., Zeng, X., Ao, Y., Liu, Q., Liu, G., Lo, W.H., Jabs, E.W., Amzel, L.M., Shan, X., Zhang, X. Mutations in HOXD13 underlie syndactyly type V and a novel brachydactylysyndactyly syndrome. Am J Hum Genet 2007;80:361-371.

33. Fantini, S., Vaccari, G., Brison, N., Debeer, P., Tylzanowski, P., Zappavigna, V. A G220V substitution within the N-terminal transcription regulating domain of HOXD13 causes a variant synpolydactyly phenotype. Hum Mol Genet 2009;18:847-860.

34. Bruneau, S., Johnson, K.R., Yamamoto, M., Kuroiwa, A., Duboule, D. The mouse Hoxd13(spdh) mutation, a polyalanine expansion similar to human type II synpolydactyly (SPD), disrupts the function but not the expression of other Hoxd genes. Dev Biol 2001;237:345-353.

35. Kuss, P., Villavicencio-Lorini, P., Witte, F., Klose, J., Albrecht, A.N., Seemann, P., Hecht, J., Mundlos, S. Mutant Hoxd13 induces extra digits in a mouse model of synpolydactyly directly and by decreasing retinoic acid synthesis. $J$ Clin Invest 2009;119:146-156.

36. Muragaki, Y., Mundlos, S., Upton, J., Olsen, B.R. Altered growth and branching patterns in synpolydactyly caused by mutations in HOXD13. Science 1996;272:548-551.

37. Debeer, P., Bacchelli, C., Scambler, P.J., De Smet, L., Fryns, J.P., Goodman, F.R. Severe digital abnormalities in a patient heterozygous for both a novel missense mutation in HOXD13 and a polyalanine tract expansion in HOXA13. $J$ Med Genet 2002;39:852-856.

38. Kuru, I., Samli, H., Yucel, A., Bozan, M.E., Turkmen, S., Solak, M. Hypoplastic synpolydactyly as a new clinical subgroup of synpolydactyly. J Hand Surg 2004;29:614-620.

39. Horsnell, K., Ali, M., Malik, S., Wilson, L., Hall, C., Debeer, P., Crow, Y. Clinical phenotype associated with homozygosity for a HOXD13 7-residue polyalanine tract expansion. Eur J Med Genet 2006;49:396-401.

40. Spitz, F., Montavon, T., Monso-Hinard, C., Morris, M., Ventruto, M.L., Antonarakis, S., Ventruto, V., Duboule, D. A t $(2 ; 8)$ balanced translocation with 
breakpoints near the human HOXD complex causes mesomelic dysplasia and vertebral defects. Genomics 2002;79:493-498.

41. Sugawara, H., Egashira, M., Harada, N., Jakobs, T.C., Yoshiura, K., Kishino, T., Ohta, T., Niikawa, N., Matsumoto, N. Breakpoint analysis of a familial balanced translocation $\mathrm{t}(2 ; 8)(\mathrm{q} 31 ; \mathrm{p} 21)$ associated with mesomelic dysplasia. J Med Genet 2002;39:34.

42. Kmita, M., Tarchini, B., Zakany, J., Logan, M., Tabin, C.J., Duboule, D. Early developmental arrest of mammalian limbs lacking HoxA/HoxD gene function. Nature 2005;435:1113-1116.

43. Zakany, J., Duboule, D. The role of Hox genes during vertebrate limb development. Curr Opin Genet Dev 2007;17:359-366.

44. Kleinjan, D.A., van Heyningen, V. Long-range control of gene expression: emerging mechanisms and disruption in disease. Am J Hum Genet 2005;76:8-32.

45. Kleinjan, D.A., Lettice, L.A. Long-range gene control and genetic disease. $A d v$ Genet 2008;61:339-388.

46. Spitz, F., Duboule, D. Global control regions and regulatory landscapes in vertebrate development and evolution. Adv Genet 2008;61:175-205.

47. Tarchini, B., Duboule, D. Control of Hoxd genes' collinearity during early limb development. Dev Cell 2006;10:93-103.

48. Morey, C., Da Silva, N.R., Perry, P., Bickmore, W.A. Nuclear reorganisation and chromatin decondensation are conserved, but distinct, mechanisms linked to Hox gene activation. Development 2007;134:909-919.

49. Montavon, T., Le Garrec, J.F., Kerszberg, M., Duboule, D. Modeling Hox gene regulation in digits: reverse collinearity and the molecular origin of thumbness. Genes Dev 2008;22:346-359.

50. Soshnikova, N., Duboule, D.. Epigenetic temporal control of mouse Hox genes in vivo. Science 2009;324:1320-1323. 


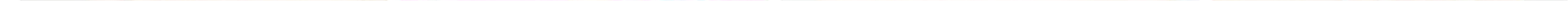



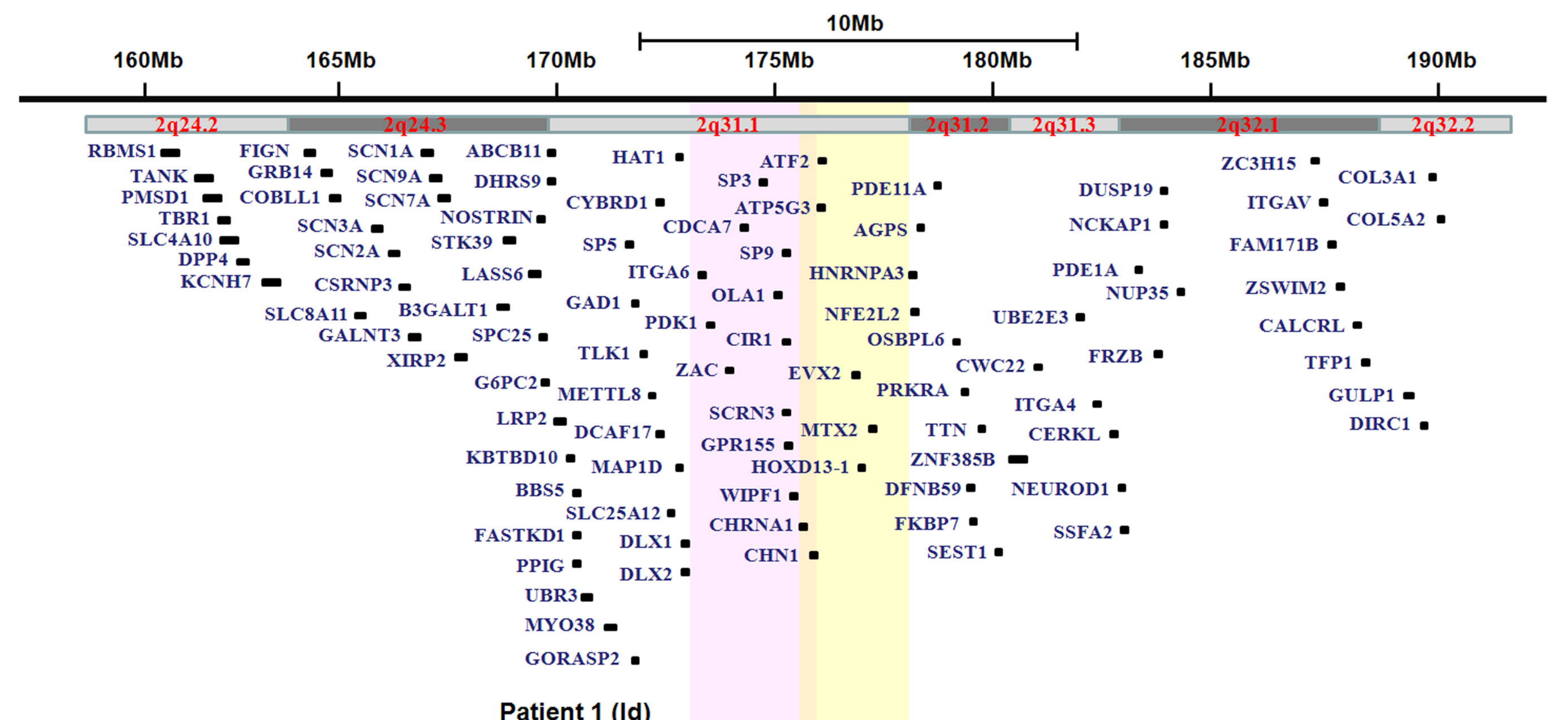

Patient 1 (Id)

Patient 2 (Id)

Patient 4 (no Id)

Patient 3 (Id)

Patient 5 (no Id)

Nixon et al., 1997 (Id) [5]

Slavotinek et al., 1999, p1 (Id) [6]

Slavotinek et al., 1999, p2 (Id) [6]

Del Campo et al., 1999, p1 (m/e) [7]

Del Campo et al., 1999, p2 (m/e) [7]

Goodman et al., 2002, p1 (SPD) [4] -

Goodman et al., 2002, p2 (m/e) [4]

Bijlsma et al., 2005 (m/e) [9]

Pescucci et al., 2007 (Id) [13]

Svensson et al., 2007 (Id) [12]

Monfort et al., 2008 (Id) [14]

Prontera et al., 2009 (Id) [15]

Tsai et al., 2009 (pp) [16]

Spitz et al., 2002 (md) [40]

- Dlugaszewska et al., 2006 (SPD), p1 [23]

- Dlugaszewska et al., 2006 (m/e), p2 [23]

- Dlugaszewska et al., 2006 (m/e), p3 [23]

B)
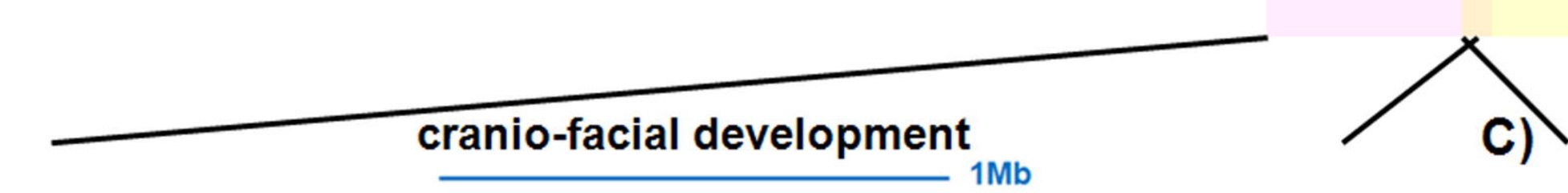

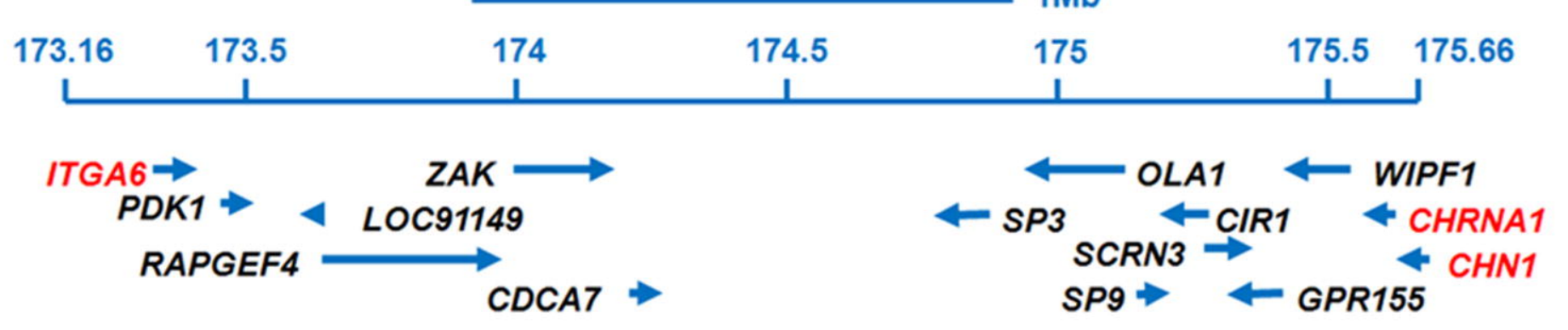

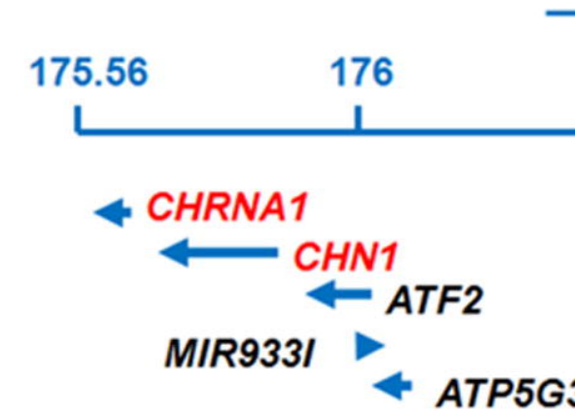

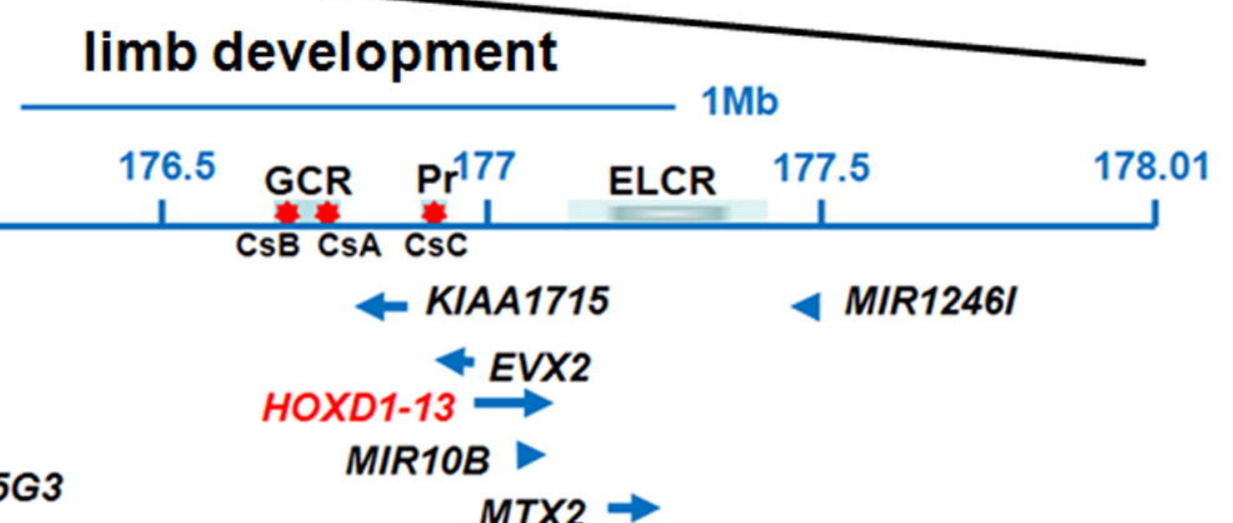

